\title{
Low Serum Folate Level and Increased Risk of Invasive Cervical Cancer in Bangladeshi Women
}

\author{
JANNATUL FERDOUS ${ }^{1}$, SABERA KHATUN ${ }^{2}$, SUBRATA KUMAR BISWAS ${ }^{3}$, SHAHANA PERVIN ${ }^{4}$, \\ LATIFAAKTER ${ }^{5}$, KASHFIAAHMED KEYA ${ }^{6}$, MITA JOARDER ${ }^{7}$, JAWAD MAHRUJ KHAN ${ }^{8}$
}

\begin{abstract}
:
Objective(s): The aim of this study was to evaluate the risk of cervical cancer in relation to serum concentrations of folate.

Materials and methods: This case-control study was conducted in the Gynaecologic Oncology Division of Bangabandhu Sheikh Mujib Medical University from November 2015-October 2016. For this study 50 patients with invasive cervical cancer were taken as study population and 50 healthy women of VIA or paps negative were taken as control to observe and compare serum folate level. Exclusion criteria were women with conditions associated with low folate level. Outcome variable was serum folate level and a $p$ value of $<0.05$ was considered as significant.

Results: Most of the participants belonged to age group 35 to 55 years in both the groups. Most of the study cases had low income status than the control group. Maximum patients with cervical cancer took OCP in comparison to control. Majority of the patients with cervical cancer had significantly low level of serum folate $(<2.7 \mathrm{ng} / \mathrm{ml})$ than those in the control group (2.7-16.1ng/ml), $p=000$.

Conclusion: A significantly low level of serum folate, was observed in patients with invasive cervical cancer. So dietary interventions with folate supplementation might have some role in prevention of cervical carcinoma.
\end{abstract}

Key words: Cervical cancer, Folate.

\section{Introduction:}

Cervical cancer is a disease of significant worldwide morbidity and mortality. There were about 530000 new cases of and 275000 deaths due to cervical cancer worldwide in $2008^{1}$. The burden of cervical cancer is disproportionately high in developing world ${ }^{2}$. In Bangladesh cervical cancer accounted for approximately $7.8 \%$ of all gynaecological patients and $70 \%$ of all gynaecological malignancies admitted in BSMMU in the year $2007^{3}$. Though cervical cancer is preventable, yet it is an important cause of disability and death of women in Bangladesh as many women present at late stage of the disease.
It is evident that human papilloma virus (HPV) is a necessary cause of cervical cancer ${ }^{4}$. However, only a small fraction of women infected with HPV will eventually develop cervical cancer. Alteration of host genes that control viral gene expression, integration of viral DNA into the host genome and disruption of cell cycle regulation are required for persistence of the virus ${ }^{5}$. Several cofactors that might facilitate this progression are hormonal factors such as oral contraceptive pill, multiparity, immunologic factors, smoking, and poor nutrition 6 . Epidemiologic studies suggest that dietary factors may influence risk for cervical cancer. Part of the effect of diet may be attributable to the suppressive action of certain micronutrients on HPV infection, particularly carotenoids and folate ${ }^{6}$.

1. Associate Professor, Division of Gynaecological Oncology, Department of Obstetrics \& Gynaecology, Bangabandhu Sheikh Mujib Medical University (BSMMU).

2. Head, Division of Gynaecological Oncology, Department of Obstetrics \& Gynaecology, Bangabandhu Sheikh Mujib Medical University (BSMMU).

3. Associate Professor, Dept. of Biochemistry (BSMMU)

4. Associate Professor, Department of Gynaecological Oncology, National Institute of Cancer Research \& Hospital.

5. Medical Officer, Department of Obstetrics \& Gynaecology, BSMMU.

6. Colposcopist, Department of Obstetrics \& Gynaecology, BSMMU.

7. MS student, Department of Obstetrics \& Gynaecology, BSMMU.

8. Student, Grade XII, Scholastica. 
Interactions appear to exist between folate status, mutations in the folate-dependent enzyme methylenetetrahydrofolate reductase (MTHFR), plasma homocysteine, and HPV- related cervical dysplasia ${ }^{7}$. Lack of folate causes accumulation of homocysteine in the blood. Folate is needed to metabolize homocysteine in one-carbon metabolism. In one-carbon metabolism, homocysteine accepts a methyl group from 5-methyltetrahydrofolate to form methionine in a vitamin $B_{12}$ dependent reaction ${ }^{8}$. Elevated levels of homocysteine have been associated with low levels of folate. Methylen-tetrahydrofolate reductase (MTHFR) catalyzes the formation of 5-methyltetrahydrofolate, the source of the methyl group needed for homocysteine to be converted to methionene ${ }^{8}$. Thus homocysteine can be degraded in our body which is needed very certain amount and too much of it is dangerous. It has been shown in a study that daily supplementation with folic acid of $0.8 \mathrm{mg} /$ day typically lowers homocysteine level by about $25 \%{ }^{9,10}$. This study was carried out to see the level of serum folate in patients with invasive cervical cancer, so that the development and progression of cervical cancer can be prevented by taking the dietary interventions.

\section{Materials and Methods:}

This case-control study was conducted in the Gynaecologic Oncology Division of the Department of Obstetrics \& Gynaecology of Bangabandhu Sheikh Mujib Medical University (BSMMU), Dhaka, from November 2015-October 2016. Study population was patient attending the Gynaenocologic Oncology Division of BSMMU with cervical cancer.

For this study 50 patients with invasive cervical cancer were taken as study population and 50 healthy women of VIA or paps negative were taken as control to observe and compare serum folate level. Sample was taken as convenience. The age range of study population was 30-65 years and disease was confirmed by histopathology. The control group was consisted by the healthy population of age range 3065 years who came for cervical cancer screening and who found VIA or Pap's smear negative. Patients with conditions associated with low level of folate like pregnancy, previously treated cervical cancer and precancer, malignancy of any other organ, diabetes, osteoporosis, cardiovascular, neurological and renal disease, medication with anti-convulsants, BMIÃ 30 $\mathrm{kg} / \mathrm{m}^{2}$, smoking, alcoholism, drug addiction were excluded from this study. Primary selection of the cases were made from history and physical examination and histopathological report of cervical growth. These primarily selected patients were approached for inclusion in the study as the cases. Detailed information relevant to the study was recorded in a properly designed pretested data collection sheet. General examination, per abdominal examination and pelvic examination was done for staging of cervical cancer. In selected cases examination under anaesthesia (EUA) was performed to confirm the staging. Social class of participants were assessed by monthly income and educational level of them.

Serum folate was estimated from blood of both control and study population. With all aseptic precaution 4-5 $\mathrm{ml}$ of fasting blood (6-8 hour fast) was collected from a convenient vein of a participant with a disposable plastic syringe and was delivered into a clean dry plastic tube. It was kept in standing position till clot formation. Then serum was separated from cells by centrifugation ( 5 minutes at $3000 \mathrm{rbm}$ ) and was stored at -27úc until the estimation of serum folate.

The folic acid level was determined using the ARCHITECT Folate assay, using protocols commonly referred to as Chemiflex. The data was coded as low (<2.7), normal (2.7-16.1) and high(>16.1)

The protocol of the study was approved by the Institutional Review Board (IRB) of BSMMU Dhaka. Informed written consent was taken from all participants prior to study initiation.

Data was analyzed using SPSS version 17 (SPSS Incorporation, Chicago, IL, USA). Outcome variable was serum folate level. The results have expressed as the mean \pm SD for the continuous variables and the categorical variables as frequency and percentage. $1^{2}$ test has been used for analysis of all categorical variables. Unpaired $i t^{\prime}$ test was performed for quantitative parameters. P value Â0.05 have considered as significant.

\section{Results:}

Patients' characteristics regarding age, BMI, parity were similar in both cervical cancer group and healthy control group. Most of the participants belong to 35-55 years range group in both cases and control group. About three- fourth of the participants were multiparous in both cases and control group. There was a significant difference in social class. In cervical cancer group low social class were $74 \%$ in comparison to healthy women where low social class was $40 \%$. $\mathrm{P}$ is $<0.05$. There was also significant difference in OCP use. Among cervical cancer group pill users were $86 \%$ and in healthy women it was only $16 \% \mathrm{p}<0.05$. (Table I).

There was a significant difference in serum folate level between two groups of women, which was $1.52 \pm 2.28$ vs $7.10 \pm 4.81$ in cervical cancer group and healthy control group respectively. Eighty eight percent (88\%) of cervical cancer group had very low level of folate $(<2.7 \mathrm{ng} / \mathrm{ml})$ but among healthy women only $12 \%$ had the same $p$ is $<0.05$ (Table II). 
Table-I

Patients' characteristics

\begin{tabular}{|c|c|c|c|c|c|}
\hline Parameter & \multicolumn{2}{|c|}{$\begin{array}{c}\text { Case } \\
\text { Mean } \pm \text { SD }\end{array}$} & \multicolumn{2}{|c|}{$\begin{array}{c}\text { Control } \\
\text { Mean } \pm \text { SD }\end{array}$} & Significance \\
\hline Age & \multicolumn{2}{|c|}{$48.76 \pm 9.50$} & \multicolumn{2}{|c|}{$40.60 \pm 6.48$} & 0.590 \\
\hline \multirow[t]{2}{*}{$B M I$} & \multicolumn{2}{|c|}{$22.06 \pm 2.75$} & \multicolumn{2}{|c|}{$21.02 \pm 2.27$} & 0.575 \\
\hline & Median & (Range) & Median & (Range) & 0.110 \\
\hline Parity & $\begin{array}{r}4 \\
\mathrm{~N}\end{array}$ & $\begin{array}{c}(2-7) \\
(\%)\end{array}$ & $\begin{array}{l}3 \\
N\end{array}$ & $\begin{array}{l}1-6) \\
(\%)\end{array}$ & \\
\hline Social class & & & & & \\
\hline High & 2 & 4 & 24 & 48 & 0.001 \\
\hline Middle & 11 & 22 & 6 & 12 & \\
\hline Low & 37 & 74 & 20 & 40 & \\
\hline OCP user & 43 & 86.0 & 8 & 16 & 0.000 \\
\hline
\end{tabular}

Table-II

Serum folate level of the study population

\begin{tabular}{|c|c|c|c|c|c|}
\hline Serume Folate & & & & & Significane \\
\hline (ng/ml) & & & & & 0.000 \\
\hline & $\mathrm{N}$ & $\%$ & $\mathrm{~N}$ & $\%$ & \\
\hline$<2.7 \mathrm{ng} / \mathrm{ml}(\mathrm{Low})$ & 44 & 88 & 6 & 12 & \\
\hline $2.7-16.1 \mathrm{ng} / \mathrm{ml}$ (Normal) & 06 & 12 & 43 & 86 & \\
\hline$>16.1 \mathrm{ng} / \mathrm{ml}$ (High) & 00 & 00 & 1 & 02 & \\
\hline
\end{tabular}

\section{Discussion:}

Cervical cancer is the most common cancer of the female genital tract in our country. The incidence is high in rural areas, where prevention and screening programs are not easily available ${ }^{11,12}$. Epidemiological studies suggest that micronutrients in diet play a significant role in maintaining health and preventing disease, including cancer. The relationship between pathogenesis of cervical cancer and folate was first described by Whitehead et al who reported that administering folic acid reversed megaloblastic changes in cervical epithelium ${ }^{13}$. Butterworth et al extended the finding to cervical dysplasia in $1982^{14}$. Folate has protective role in the etiology of cervical cancer ${ }^{15}$. Folate's possible protection against cervical cancer is based on its roles in DNA synthesis and repairing damaged $D N A^{16}$. Folate is involved in DNA methylation through which it may influence gene stability and expression ${ }^{16}$.

Several case-control studies have been conducted to investigate the relation between folate and cervical dysplasia or cervical cancer. In this study, fifty (50) patients with histopathologically confirmed invasive cervical cancer as cases and fifty women having healthy cervix revealed by screening test (VIA or pap) as controls were included. Both cases and control were almost identical in terms of age, parity, occupation, education and BMI, which are the potential confounders that may affect the risk for cervical cancer as well as serum folate level. But significant difference was observed in OCP use and monthly income of the study subjects.

It is reported that cervical cancer has two peaks, one at about 35 years and another at about $50-55$ years ${ }^{17}$. In this study most of the participants belonged to age group 35 to 55 years that reflects one of the bimodal incidence of cervical cancer.

Monthly income of cervical cancer patients in this study was also significantly lower than that of control. Most of the cases (60\%) had from low monthly income whereas majority of the controls had average to high monthly income. Carcinoma cervix is more prevalent amongst women living in poor condition with a low income status ${ }^{17}$. The difference in monthly income in this study also indicate that cervical cancer patients with low income conditions are associated with 
deficient nutrition whereas controls with relatively higher monthly income have improved nutritional reserve with higher level of folate which is protective against cancer.

Oral contraceptive pill use is a risk factor for cervical cancer. There is also high correlation between serum folate and OCP use ${ }^{18}$. The possible confounding effect of OCP use on the assessment of the effect of folate in study groups may happen as $86 \%$ of women in cervical cancer patients and $16 \%$ of patients in control used OCP and the difference was statistically significant. So, larger sample size is required to eliminate this selection bias.

Several studies have showed that BMI has influence on folate level. Serum folate decreases with increase in the body size ${ }^{19}$. In the present study majority of the participants had BMI between $18.5-25 \mathrm{~kg} / \mathrm{m}^{2}$ and there was no statistical difference between the mean BMI between the two groups.

This study shows that majority of the patients with cervical cancer $(88 \%)$ had low level of folate $(<2.7 \mathrm{ng} /$ $\mathrm{ml})$; whereas in the control group majority of the participants $(86 \%)$ had normal level of folate (2.7$16.1 \mathrm{ng} / \mathrm{ml}$ ) and it was statistically significant.

These finding correlate with some studies, which found that higher folate level is associated with significantly reduced risk of cervical cancer ${ }^{20-26}$.

So, nutrient supplementation especially folate is necessary in preventing development of cervical precancers and cancers ${ }^{26}$.

\section{Limitations of the study:}

In this study, women were not tested for HPV infection, which is the necessary cause of cervical cancer. Although some authors of different studies argued that test for HPV infection should be done for precise interpretation of findings, it is revealed that studies taking HPV infection into account do not differ substantially from those studies that did not control for it. Moreover, further studies with large sample size is needed to establish the association between low level of serum folate and invasive cervical cancer.

\section{Conclusion:}

A significantly low level of serum folate was observed in patients with invasive cervical cancer compared to that in women with healthy cervix. Malnutrition is a risk factor of cervical cancer. Women at risk of developing cervical cancer can be given advice to increase intake of vegetables. Public awareness regarding intake of fresh vegetables, fruits to increase serum folate level can be created and women of all reproductive age group can be encouraged to take plenty of vegetables, fruits and folic acid supplementation to prevent cervical cancer.

\section{Acknowledgement:}

I would like to thanks Research Grants Committee of BSMMU and University Grants Commission for funding this research. I am grateful to all the doctors and stuffs of the department of Biochemistry for their sincere help in conducting the research.

\section{References:}

1. Ferlay J, Shin HR, Bray F, Forman D, Mathers $\mathrm{C}$ and Parkin DM. GLOBOCAN 2008 V 1.2, Cancer Incidence and Mortality Worldwide: IARC Cancer Base No.10.Lyon, France:International Agency for Research on Cancer;2010.Available from:http//globocan.iarc.fr.accessed on 20/5/ 2012.

2. Parkin DM, Bray F, Chapter2: the burden HPVrelated cancers. Vaccine. 2006; 24 (suppl 3): S 11-25.

3. Ferdous J,Begum SA, Feedous NE,Nahar Q, Khatun SF ,Khatun S. Presentation of Invasive Cervical Cancer in Bangladesh.BSMMU J 2013; $6(1): 29-32$

4. Munoz, N. Human papillomavirus and cancer: the epidemiological evidence. J.Clin. Virol 2000;19:1-5.

5. Zur Hausan H. Papillomavirus causing cancer: Evasion from host-cell control in early events in carcinogenesis. J . Nati. Cancer Inst.2000; 92:690-698.

6. Schiffman MH, Brinton IA, Devesa SS,Fraumeni IF .Cervical Cancer. Schottenfield, D. Fraumeni, J. F, Jr. eds . Cancer Epidemiology and Prevention $2^{\text {nd }}$ ed: 1090-1116 Oxford University Press New York.

7. Butterworth CE Jr, Hatch KD, Macalusa M. Folate deficiency and cervical dysplasia. JAMA. 1992; 267:528-533.

8. Ziegler RG, Weinstein SJ, Fears TR. Nutritional and genetic inefficiencies in one-carbon metabolism and cervical cancer risk. J.Nutr. 2002 ;132 : 23455-23495. 
9. Armitage JM. Lowering Homocysteine Levels With Folic Acid and Vitamin $B_{12}$ Does Not Appear to Reduce Risk of Heart Attack, Stroke,Study Finds. Science Daily.2010; 47(2):72-123.

10. Wald DS, Bishop L, Wald NJ, Law M, Hennessy E ,Weir D .Randomized trial of folic acid supplementation and serum homocysteine. Arch Intern Med 161(5):695-700.

11. Duttagupta, C., Sengupta, S., Roy, M., Sengupta, D., Chakraborty, S., Bhatacharya P., et al. Oncogence human papillomavirus (HPV) infection and uterine cervical cancer: a screening strategy in the perspective of rural India. Eur J Cancer prev 2002;11: 4477-56.

12. Radhakrishna, P.M., Sreevidya, S., Pollock, B.H., Jayaprakash, P.G., Herman, Human papillomavirus type $16 \mathrm{E} 6$ and $\mathrm{E} 7$ gene variations in Indian cervical cancer. Gynecol Oncol 2002; 87:268-73.

13. Whitehead N, Reyner F, and Lindenbaum J. Megaloblastic changes in the cervical epithelium. J.Am. Med. Assoc.226:1421-1424, 1973.

14. Butterworth CE, Hatch KD, Gore H, Mueller H, and Krumdieck CL. Improvement in cervical dysplasia associated with folic acid therapy in users of oral contraceptives. Am. J. Clin Nutr. 35: 73-82, 1982.

15. Butterworth C. E. Effect of folate on cervical cancer. Ann. N.Y. Acad. Sci,1992; 669: 293-299; 1992.

16. Mason JB and Levesque T. Folate: effects oncocarcinogenesis and the potential for cancer chemoprevention. Oncology ( Basel) 1996; 10: 1727-1742.

17. Jefffcoate. (2008) Jeffcoate's Principles of Gynaecology. Revised and updated by Pratap Kumar and Narendra Malhotra $7^{\text {th }}$ edition. New Delhi: Arnold: p-467-68.
18. Willett, W. (1998). Nutritional Epidemiology. $2^{\text {nd }}$ ed. New York: Oxford University Press: 174-243

19. Mojtabai, R. Body mass index and serum folate in childbearing age women. Eur $\mathrm{J}$ Epidemiol 2004;19:1029.

20. Alberg, A.J., Selhub, J., Shah, K.V., Viscidi, R.P., Comstock, G. W., Helzlsouer, K.J. The risk of cervical cancer in relation to serum concerrations of folate. Vitamin B12, and homocysteine. Cancer Epidemiology Biomarkers and Prevention.2000; 9:761-4

21. Goodman, M.T., McDuffie, K., Hernandez B, Wilkens L.R., Selhub, J. Case-control study of plasma folate, homocysteine vitamin B12, and cysteine as markers of cervical dysplasia. Cancer Phila 2000; 89:376-82.

22. Goodman, M.T., McDuffie, K., Hernandez B., Wilkens, L.R., Bertram, C.C., Killen, J., et al. Association of methylentetra- hydrofolate reductase polymorphism C677T and dietary folate with the risk of cervical dysplasia. Cancer Epidemiol Biomarkers Prev2001; 10:1275-80.

23. Piyathilake, C.J., Macaluso, M., Alvarez, R. D. Lower Risk of Cervical Intraepithelial Neoplasia in Women with High Plasma Folate and Sufficient Vitamin B12 in the Pos-Folic Acid Fortification Era. Cancer Prev Res 2009; 2 (7): 658-664.

24. Sebjo, R.L., Inserra, P., Abrahamsen, M., Harris, R.b., Roe, D.J., Baldwin, S., et al. Human papillomavirus persistence and nutrients involved in the methylation pathway among a cohort of young women. Cancer Epidemiol Biomarkers Prev, 2002;11:353-9.

25. Sedjo, R.L., Fowler, B.M., Schneider, A., henning, S.M., hatch, K., Giuliano, A.R. Folate, vitamin $\mathrm{B} 12$, and homocysteine status. Findings of no relation between human papillomavirus persistence and cervical dysplasia. Nutrition. 2003; 19 (6):497-502.

26. Keri Marshall, N.D.Cervical Dysplasia: Early Inervention. Alternative Medicine Review2003; 8 (2): 156-70. 